\title{
ERP-based Business Accounting and Finance Management
}

\author{
Qian Liu \\ Chongqing Vocational Institute of Engineering, Chongqing, 402260, China
}

\begin{abstract}
Keywords: Finance management, ERP system, Enterprise development
\end{abstract}
\begin{abstract}
As China's economic development level keeps on improving, market economy is ever-changing. With the progress and development of computer technology, business accounting and finance management also becomes informatized and programmed. The wide application of SRP system exerts profound influence on business accounting and finance business accounting and finance management. ERP can obtain accurate results in both data integration and problem analysis and can offer reliable basis for business accounting and finance management. Considering business accounting and finance play a $n$ increasingly great role in enterprises, ERP system is also under continuous improvement and development in order to enable enterprises to gain more economic benefits and social benefits.
\end{abstract}

\section{Introduction}

In recent years, ERP system has been widely applied in business accounting and finance work and can integrate and optimize various resources of an enterprise. Hence, it is an important means in business accounting management. Less management software was applied in original business finance management, and traditional method was used to handle financial work. This does not contribute to improving work efficiency and integrating resources and cannot reach the set objective. The application of ERP system in business accounting and finance management can carry out financial work in combination of actual conditions of an enterprise. The system breaks through and develops the inherent mode. This paper analyzes the application of ERP in business accounting and finance management as follows.

\section{Overview of ERP}

Brief introduction to ERP. ERP refers to Enterprise Resource Planning which appeared in an American computer company in 1990s. To meet the demand of IT development and supply chain and better conform to development requirements of business management information system, this concept was proposed. The system can integrate and optimize information of material resource management, human resource management and business finance management, and integrate them into management software. ERP system involves open system software making, information flow integration, port used by graphs and service architecture at each level and so on. Besides, it owns some standardized functions which can manage and report product features ${ }^{[1]}$. Seeing from Chinese and overseas business development history, finance management mode has experienced many evolutions and it is basically in a mingled state of centralization and decentralization. From 1990s, BPR-cored management reform formally started. Almost all companies were reorganized to reconstruct centralized finance management mode. Nowadays, many enterprises still adopt independent decentralization mode to manage business finance. In other words, subsidiary corporations at each level are responsible for their own internal accounting and finance management, while the head office just needs to deploy or guide subsidiary corporations as well as guide and check financial audit of subsidiary corporations at regular intervals. Such finance management mode is similar to that in 1980s-1990s. Besides, many Chinese enterprises have complex and diversified organization forms, institutional frameworks and management modes, which also results in complexity and diversity features of finance management mode. Therefore, it is especially important to actively explore finance management mode suitable for enterprise development. 
Connotation. Accounting and finance management is a significant content in enterprise development, and concerns future development direction and market position of an enterprise. The emergence of ERP system brings a new opportunity for business accounting and finance development. Compared with traditional accounting and finance, ERP system can improve work efficiency from different aspects, enhance profit space, strive for greater competitive edge for an enterprise in future development and improve enthusiasm for production. The connotation of ERP business accounting and finance management is reflected in the following aspects:

Firstly, ERP can conduct integration and centralized management of enterprise resource supply chain, efficiently combine scattered information flow and make logistics, capital flow and information flow interact and reach unification. Secondly, ERP can meet the demand of production, precision production and synchronous production to the largest extent. As the market tends to be saturated, many new products are ignored and cannot be accepted by consumers. Only few people will actively purchase ${ }^{[2]}$. After ERP is used, business finance management can not just assist finance planning and offer single statement, but also can help an enterprise prepare the statements of the next quarter or the next year, provide basis for business decision-making and make the enterprise keep up with era development and gain competitive advantage in market.

\section{Influence of ERP on business accounting and finance management}

ERP can integrate various information resources in an enterprise. Even if some Chinese enterprises are actively carrying out extensive cooperation with international famous enterprises, the effects achieved are very few in actual development process, and various data provided by accounting and finance management are still needed for product production, manufacturing, promotion, design and marketing. Besides, data provided by business accounting and finance management are needed to guide market trend. In a bid to acquire larger market share, occupy the data provided by accounting and finance management in the market and gain more cooperation opportunities with famous enterprises, many Chinese enterprises actively introduce new accounting and finance management mode - ERP system. Such management mode enables all kinds of enterprise resources to optimize allocation, integrate information, help enterprises to reduce waste, rationally allocate human resources and decrease over-speed development ${ }^{[3]}$. For example, a clothing group in China actively cooperates with a transnational corporation in America and promotes win-win situation; both parties gain economic benefit and social benefit. On the one hand, this enterprise signs cooperation project with American enterprise. The cooperation scope covers the sweater factory of the clothing enterprise. The cooperation items include production management, sales management, purchasing management, plan management and logistics management etc. The cooperation duration is 6 months. The project signed by the Chinese enterprise and American enterprise is divided into three steps: monitoring and managing product logistics and production; integrating and standardizing logistics fund, making financial information open and transparent; monitoring and optimizing distribution link and supply chain link to make each link of product circulation standard and qualified. ERP mode is applied in this project cooperation. The application of ERP mode exerts great influence on business accounting and finance. It optimizes many aspects, reduces information asymmetry, and helps the enterprises master the latest information so as to achieve optimal use of information.

ERP can make enterprise decision-making more timely and convenient. At present, many enterprises adopt ERP system, and its functions are standing out. ERP can not merely bring help for business accounting and finance work, but also really implement each task. With strong execution force, it fully mobilizes employees' working enthusiasm. However, it also has some defects. In fierce market competitions, many market conditions cannot be altered at will, so enterprise development is faced with obstructions. Thus, enterprises must start internally to seek breakthroughs. Business accounting and finance management generates direct influence on enterprise development. ERP may be applied to optimize financial work, construct standard mechanism, make problem solving more standard and rational, facilitate routine accounting work and auditing work to follow laws, and rules and prevent work errors. For instance, as market information changes continuously, ERP can 
automatically acquire enterprise-related market information according to actual development situation, which helps enterprises realize timely information acquisition and utilization, occupy the advantage in the market and seize the development chance. It can be seen from the above contents that, ERP can give a significant role in business accounting and finance, and enable enterprises to avoid risks, improve risk recognition ability and meet enterprise development demand.

In general, ERP owns many advantages. Practice has proven that it can increase production fund turnover rate to $30 \%-50 \%$, increase production efficiency to $20 \%-30 \%$, decrease production cost to $5 \%-8 \%$ and increase profit to about $10 \%$. In one word, ERP can concentrate functions of production departments at each level in an enterprise for management and optimization, and store information in a computer. However, ERP implementation is also complex, and confronted with many risks, e.g. how to optimize system integration problem; how to enhance optimization effect; how to better process port or data. In addition, ERP application needs certain cost. Essentially, ERP system has very strong management thought. It is a management mode with planning nature under principal production. Meanwhile, it puts forward higher requirements for organizations, posts, business and personnel. Business data collection, statement preparation and information transmission should be done well. The leaders also need to improve management and decision-making ability, actively educate and train employees ${ }^{[4]}$.

\section{Examples of ERP application in business accounting and finance management}

An enterprise is a trans-regional large-scale enterprise which integrates cultivation, cultivation and processing. Its core industry includes raising chickens and pigs. Meanwhile, the group also carries out cow breeding, agricultural product and by-product processing. Downstream industry involves vaccine production and veterinary medicine processing. These form a complete group with the core industry. The group always sticks to triangle mode of "company + base + household" in development process, which embodies integrated breeding mode. Fodders used to raise chickens are provided by the group. Then, the baby chicks are sent to households' breeding base. Finally, the enterprise purchases and sells chickens uniformly. Under such mode, all kinds of elements achieve integration and concentration, and large quantities of orders can be ensured every day. More than 40000 households take baby chicks and fodders from the group annually. It is especially important to make operation records and classification well for these orders. ERP products can be produced under industrial norms, but households cannot transfer the farm into the enterprise. So they cannot apply ERP mode, let alone apply ERP of other enterprises. Meanwhile, they cannot buy software. "Company + base + household" production mode cannot be solved by ERP of any enterprise in China. But, the enterprise keeps on studying the advanced idea and concept of ERP, then combines field investigation, test and evaluation and finally chooses Kingdee EAS standardized products + EAS BOS customization mode as the new production and operation mode of the enterprise. Such new mode betters comprehends the intention of decision makers and makes the enterprise take the way of wider development.

ERP management information platform brings development advancement, so the group really achieves integrated operation and systematic management. Firstly, the implementation of financial work is mot standard and rational in the breeding process of peasant households, and financial disputes decrease. In addition, the full breeding process, breeding technology, financial accounting and management are fused in the system. From taking baby chicks to breeding completion, each procedure can be recorded, and nay step can gain guidance. Secondly, uniform deployment of breeding, transportation and sales is achieved, and financial business also becomes integrated. There is a fixed feature in breeding industry sale, i.e. order-based sales. As long as there are sufficient orders, more profits can be created. Moreover, most products in animal husbandry are living creatures, which puts requirements for transportation time. To keep fresh of living creatures, transportation duration cannot exceed $200 \mathrm{~km}$. once this time is exceeded, product quality will lower. Thus, the goods should not be delivered unless the order is received. At the same time, delivery should be in time and cannot be delayed. In view of such particularity, the production period should be $0.5-1$ year ahead, and the seedling cultivation also should be 0.5 year ahead. With EAS information platform, top-bottom 
full-process management of cultured products is achieved on the basis of orders. Thirdly, with such integrated mode, the group can achieve integrated management in such links as raw material procurement, production and transportation. Since fodder procurement production and transportation links have particularity (such as many transfer stations, truck transportation and large loss in transportation process), it is necessary to optimize and manage the whole process from raw material procurement, production and transportation to payment. With ERP support, the group can manage baby chick and fodder taking of every peasant household, supervise medicines, purchase and sell chickens well. Hence, group decision achieves transfer smoothly and financial accounting keeps consistent with finance management. Meanwhile, importance of finance management is reflected truly and objectively, and practically implemented.

\section{Conclusion}

As China's information technology keeps development and progress, the policy of "promoting industrialization by informatization" is being implemented actively. Thus, the significance of information technology gradually stands out. In particular, small and medium-sized enterprises in development stage, on the one hand, seek the methods to occupy more market shares; on the other hand, they enhance cooperation with famous enterprises. ERP can optimize and combine group management process. It regards accounting and finance as enterprise development core and root, takes financial accounting as the foundation and deems financial standards as the impetus and considers strategic planning as the support to really achieve full-process management.

\section{References}

[1] Li Yongdong, Study on ERP System Application in Business Accounting and Finance Management. Value Engineering, 2010,29(20):39-40.

[2] Liu Weimin, Improvement of Business Accounting and Finance Management Level by ERP Information System - Experience about ERP System Application in Finance. China Management Informationization, 2011(18):15-16.

[3] Li Liang, Study on CDIO Concept Application in ERP Financial Management Teaching Reform. Journal of Harbin Institute of Vocational Technology, 2013(5):75-76.

[4] Yu Tao, Exploration of J2EE Technology Application in Development of ERP Financial Accounting Management System. Journal of Qiqihar Junior Teachers' College, 2011(3):102-104.

[5] Long Xiaoyu, Dong Mingming, Comparative Analysis of Financial Management Module of ERP System - Case Study of SAP and UFIDA U8. Journal of Xi'an University of Posts and Telecommunications, 2010,15(2):93-96,117. 